\title{
Does the Primary Condition for a Sustainable Human Development Meet the Feasibility Condition of Cost-Benefit Analysis?
}

\author{
Hasnat Dewan \\ Department of Economics, Thompson Rivers University \\ 900 McGill Road, Kamloops, BC V2C 5N3, Canada \\ E-mail: hdewan@tru.ca
}

Received: January 12, 2011

Accepted: February 13, 2011

doi:10.5539/jsd.v4n2p3

\begin{abstract}
The primary condition for a sustainable human development (SHD) uses both monetary and non-monetary indicators to determine the sustainable level of human development. As defined, this condition can be expressed in terms of the damage elasticity of human development, where damage is defined based on the non-monetary cost to the natural and social environments (NSE). A comparison between this sustainability condition and the feasibility condition of cost-benefit analysis (CBA) is useful for determining the sustainability premium or the deadweight loss. Since the cost-benefit methodology uses monetary estimates of all impacts and the primary condition for sustainable human development uses both monetary and non-monetary indicators, the two methodologies are unlikely to yield the same outcome unless there is a one-to-one relationship between monetary and non-monetary benefits and costs. Unlike the feasibility condition of CBA, the primary condition for a sustainable human development varies based on the level of human development and the damage to the NSE in any locality/country.
\end{abstract}

Keywords: Sustainable human development, Cost-benefit analysis, Sustainability condition, Feasibility condition

\section{Introduction}

Different variations of cost-benefit analysis (CBA) are used for project or policy evaluations by economists. (Note 1) Assessing the sustainability of a human development policy, or any policy for that matter, with the CBA brings up many thorny issues (Gowdy and Howarth, 2007). A number of different sustainability indices and conditions have been developed in the recent years through global, national, regional, and individual initiatives for sustainability assessment. This paper will compare such a condition defined by Dewan (2009) for a sustainable human development (SHD) with the feasibility condition of CBA, and attempt to determine the deadweight loss associated with it. Though there are many definitions of SHD available in the literature, to our knowledge, no other study has attempted to find a condition for a sustainable human development. A comparison between the sustainability and the feasibility condition is useful for determining the sustainability premium, or the cost of making human development sustainable.

The cost-benefit methodology compares the present values of benefits and costs to evaluate a project or a policy. The term 'sustainability' recognizes future generations' rights in the calculation of benefits and costs. Therefore, a sustainability condition (SC) is expected to include marginal present and future benefits and costs, where costs must account for all damages to the natural and social environments (NSE) that may possibly restrain future well-being. (Note 2)

In welfare economics, benefits are measured in terms of consumption (or Hicksian income), whereas in a non-welfarist approach, economic development or benefits are measured in terms of capabilities, freedom, etc. (Sen, 1999; Nussbaum, 2000). For sustainability assessments, it is also common among natural scientists and environmentalists to ignore benefits altogether and focus only on damages to the environment (environmental sustainability). Furthermore, economists and natural scientists are often at odds in evaluating damages to the natural environment. Mainstream economists prefer monetary valuation simply because it represents the scarcity value of resources, while natural scientists prefer indices or policies that use methodologies such as physical accounting of the stocks of natural resources (Bojö, et al., 1990; Theys, 1989; Alfsen, et al., 1987), maximum sustained utilization rate for elements of the environment, or critical loads (Hall, 1993). Most economists find policies based on any such mechanism arbitrary and inefficient (Dubourg and Pearce, 1996), though many 
international agreements, such as the Kyoto Protocol, the Helsinki Protocol, etc. have used these mechanisms to ensure, in their words, sustainable use of natural resources and the environment.

The well-publicized Stern Review (Stern, 2006) on climate change, which has used somewhat compromising economic models to estimate the benefits of climate change intervention ( $1 \%$ of global GDP loss/per year) and the costs of inaction (5\%-20\% of global GDP loss/per year) has drawn criticisms from all sides. Not only have the scientific evidences used in the Review been challenged, questions have also been raised about the appropriateness of using cost-benefit methodology with positive discount rate (Beckerman, 2007). Mainstream economists point out that the 'radical' conclusions of the Review are mainly due to 'a near-zero time discount rate combined with a specific utility function' (Nordhaus, 2007) and believe that spending on climate change issue is about 'how much insurance to buy to offset the small change of a ruinous catastrophe that is difficult to compensate by ordinary savings' (Weitzman, 2007). This approach to the environment is unacceptable to many non-economists (and some economists). The use of CBA in dealing with sustainability issues has been extensively analyzed in a special issue of Ecological Economics (2007) on sustainability and cost-benefit analysis.

Beckerman (2007) has rightfully observed that there may be a temptation to 'discard traditional economic methods and established ethical systems and replace them by the concept of sustainable development' due to discount rate controversy. However, 'vagueness' of the concept sustainable development and inadequacy of standard CBA to intergenerational policy decisions have forced him to believe that the society needs 'new ideas about justice' to address intergenerational issues.

To improve the human development index, changes may have to be made to the NSE, which includes climate conditions and much more. (Note 3) Therefore, for a sustainable human development, it is essential to guarantee that life sustaining conditions on earth remain above their critical levels forever. (Note 4) The condition for a sustainable human development is expected to do that. The condition for SHD, as defined in Dewan (2009) and described in section 2.2 of this paper, is essentially a condition based on non-monetary benefit-cost ratio that includes environmental and social impact assessment into the benefit-cost calculation. Its strength is that it is immune to many of the criticisms outlined above. The computation of benefits in this methodology is consistent with a non-welfarist developmental policy. Instead of using market valuation, contingent valuation $(\mathrm{CV})$ and/or deliberative monetary valuation (DMV) to monetize all indicators, the condition for SHD uses both monetary and physical indicators to measure present and future benefits and costs.

The sustainability condition, as defined, ensures that each element (or sub-system) of NSE will always remain above the critical level, which the mainstream economic approach or the conventional cost-benefit analysis cannot guarantee, and which is the main concern of ecologists, environmentalists and many others about pure economic approach to sustainability. Since the conventional cost-benefit methodology uses monetary estimates of all impacts and the primary condition for sustainable human development uses both monetary and non-monetary indicators, the two methodologies are unlikely to yield the same outcome unless there is a one-to-one relationship between monetary and non-monetary benefits and costs.

The structure of this paper is as follows. Section 2 defines the cost-benefit methodology and the concept of sustainable human development (SHD). It also explains Dewan's (2009) primary condition for a sustainable human development. Section 3 compares the primary condition for a sustainable human development with the feasibility condition of cost-benefit analysis, and computes the deadweight loss. This section also presents a brief note on project evaluations with sustainability and feasibility conditions. Section 4 concludes.

\section{Methodology}

This section explains the cost-benefit methodology and the methodology of finding the primary condition for a sustainable human development.

\subsection{The Cost-Benefit Analysis (CBA)}

Though some of the basic concepts of CBA were developed back in the $18^{\text {th }}$ and $19^{\text {th }}$ century (Franklin, 1772; Dupuit, 1844; Marshall, 1890), it was the US Corps of Engineers that first used a formalized CBA in 1936. Since 1950s, the works of many economists have refined the CBA methodology and have made it much more rigorous. Variations of the basic CBA accounting framework are used in different disciplines. The CBA decision rule or the feasibility condition is: discounted flow of benefits from a project $\geq$ discounted flow of costs from the project. This condition can be re-arranged to find: the ratio of discounted flow of benefits to costs from a project $\geq 1$.

The CBA decision rule appears to be very simple. It compares the discounted flow of benefits from and the discounted flow of costs of a project to determine its feasibility. However, in practice, the valuation of all 
impacts extended over a period of time is not quite simple. Different valuation methods based upon option price, existence value, shadow price, contingent valuation, etc. have been used to find monetary values of benefits and costs where no direct valuation is available.

Time horizon and discounting are two critical factors in monetary evaluation of any project. Based on average capital depreciation rate and approximate length of generations, it is argued that projects with considerable impacts beyond 50 years should be considered truly intergenerational (Boardman, et al., 2006). A distinguishing factor between intra and intergenerational projects is the use of different discount rates. From fixed interest rate to various forms of time-declining discount rate are proposed as probable discount rates for CBA analysis in the economics literature. Behavioral studies show hyperbolic discount rate for human preference (Laibson, 1997; Gowdy, 2007). Weitzman's (2001) gamma discounting is another popular non-linear method of discounting.

For a single project evaluation, the feasibility condition (FC) of CBA is non-negative net present value (NPV) or a discounted benefit-cost ratio (BCR) of greater than or at least equal to one. The decision outcome is the same irrespective of the method used. However, NPV criterion is often preferred to BCR criterion when choosing between alternate projects (Boardman, et al., 2006).

Ex ante CBA is used for determining the feasibility of a project or a policy. Ex post CBA is used to find the efficacy of CBA. Flyvbjerg, et al. $(2002,2005)$ evaluated a number of transportation projects and showed that cost estimates were consistently understated and benefit estimates were overstated. For road and rail projects, they found that ex post costs were $20.4 \%$ to $44.7 \%$ higher and riderships were $20 \%$ to $51.4 \%$ lower. In another study by Harrington, et al. (2000), it was found that US regulatory cost estimates were overstated. Due to the uncertainty in expected impacts and appropriateness of monetary valuation, often the researchers perform sensitivity analysis for ex ante CBA. Yet it may be prone to 'omission errors, forecasting errors, measurement errors, and valuation errors' (Boardman, et al., 2006).

Gowdy and Howarth (2007) wrote in the preface of the special issue of Ecological Economics: "When BCA is applied to evaluate questions of 'sustainability', thorny issues such as intra-and inter-generational equity, interpersonal utility comparisons, ecological complexity, and ethics toward the non-human world come to the forefront."

Howarth (2007) states that CBA can be modified to incorporate sustainability issues, while Norton (2005), who questions the concept of 'pricing nature,' recommends for replacing CBA with 'adaptive management' (see Iovanna and Newbold, 2007). Spash (2007) points out that how various methods and concepts, e.g., willingness-to-pay (WTP), contingent valuation (CV), and deliberative monetary valuation (DMV), might 'relate to existing value theory in economics and numbers used in CBA' is unclear, and they might be 'incommensurable' (Sagoff, 1998). Dovers, et al. (1996) criticize CBA for not explicitly accounting for uncertainty. Knetsch (2007) is concerned about the disparity between willingness-to-pay and willingness-to-accept measures of environmental elements in CBA. Gowdy (2007) contends that CBA is considerably improved when non-market sources of well-being are incorporated into CBA estimates.

\subsection{Sustainable Human Development (SHD)}

The term Sustainable Human Development (SHD) has been used since 1991 with different meanings. Jolly (1991) defines SHD as protecting our children's well-being with an "integrated, human approach to environment." (Note 5) Speth (1994) defines SHD as development that is pro-poor, pro-nature, pro-jobs, pro-democracy, pro-women and pro-children. Hasegawa (2001) considers SHD and environmental sustainability as two components of sustainable development. According to the UNESCO (2010), "the interdependent links between environment and development are not simply about conservation and economics, but also include a concern for issues such as human rights, population, housing, food security, and gender that are important parts of sustainable human development."

Each of these definitions of SHD brings up different dimensions of human development policy goals to the forefront. Environmental sustainability is not the focal point in any of these definitions of SHD. Most researchers in the Human Development Paradigm consider sustainability as just another dimension of the human development policy goals, whereas many researchers in the Sustainability Paradigm believe that to be the critical issue for our future existence. Dewan (2009) defines SHD by integrating socio-cultural and environmental sustainability and human development policy goals in the definition. According to him, SHD means finding the optimum level of human development with minimum damage to the NSE in order to promote the welfare of a maximum number of people in present and future generations. This definition comes from his earlier work (Dewan, 1998), and is consistent with the triple bottom line methodology (Elkington, 1998), which is now consensually applied in different sectors for full cost accounting. 
A set of SHD indicators, similar to a set of sustainable development indicators, can be defined to assess the sustainability of human development. The Human Development Index, constructed by M. Haq, A. K. Sen, and others for the UNDP in 1990, is a measure of the level of human development. It is a composite index based upon equal weights on income, level of education, and longevity. The computational methodology of this index is stated in more detail in section 3.1 of this paper. The methodology of the Human Development Index has many limitations, but it still is a popular index to measure the level of human development. However, the Human Development Index alone cannot be an index for sustainable human development, because it cannot guarantee sustainability.

For human development to be sustainable, it must be ensured that it is achieved with sustainable means and the growth path of human development is non-negative. Climate change, deteriorated quality of environment, depletion of non-renewable natural resources, etc. are seen as potential threats to future sustainability. Therefore, all of these are real concerns for a sustainable human development. In addition to these, socio-cultural changes need to be monitored as well. Dewan (2009) defines a damage index (D) to account for changes in all of these conditions. (Note 6) He also defines a set of indicators for the necessary and the sufficient conditions for SHD. The rest of this section defines Dewan's (2009) necessary or primary condition for SHD.

In the primary sustainability condition, benefits are measured in terms of changes in the UNDP's Human Development Index (H henceforth) and costs in terms of changes in the damage index (D henceforth). Therefore, any activity is viable, if $\Delta \mathrm{H} \geq \Delta \mathrm{D}$ (for an improvement in $\mathrm{H}$ ) or $\Delta \mathrm{H} \leq \Delta \mathrm{D}$ (for an improvement in the quality of the natural and social environments or a decrease in the damage index), where $\Delta$ stands for absolute change, and both $\mathrm{H}$ and $\mathrm{D}$ are measured on the same scale. The UNDP measures $\mathrm{H}$ on a one point-scale, where its components are occasionally revised upward by the UNDP based on higher expectations. (1-H) measures the difference between actual and expected (targeted) $\mathrm{H}$. D is also measured on a one-point scale, where $\mathrm{D}=1$ means the exhaustion of a sub-component of the NSE or the falling of a component of the NSE below the critical level where the ecology or the human life is not sustainable. As innovation, technological progress and advancement of knowledge change our understanding of those critical levels we must continuously revise the damage index. It will minimize errors in decision making under uncertainty. In other words, it will lower the uncertainty or sustainability premium. (Note 7) Since D is the damage index, (1-D) is a measure of the quality of the NSE. Meeting the above condition, $\Delta \mathrm{H} \geq \Delta \mathrm{D}$ (for an improvement in $\mathrm{H}$ ) or $\Delta \mathrm{H} \leq \Delta \mathrm{D}$ (for an improvement in the quality of the NSE or a decrease in the damage index), makes an activity viable; but it cannot guarantee that the quality of the NSE or (1-D) will always remain above the critical level as required for sustainability.

Instead of using $\Delta \mathrm{H} \geq \Delta \mathrm{D}$ or $\left(\frac{\Delta H}{\Delta D}\right) \geq 1$, if we use $\frac{\frac{\Delta H}{(1-H)}}{\frac{\Delta D}{(1-D)}} \geq 1$ or $\left(\frac{\Delta H}{1-H}\right) \geq\left(\frac{\Delta D}{1-D}\right)$ or $\left(\frac{\Delta H}{\Delta D}\right) \geq\left(\frac{1-H}{1-D}\right)$ as

the sustainability condition, improving the same amount of human development at the equivalent cost of the NSE may not be sustainable, when the quality of the NSE is low as opposed to when it is high. This condition will also ensure certain minimum quality of the NSE, because when D is large, virtually no human development policy at the cost of the NSE will meet this condition. Rather, an environmental cleanup $(\Delta \mathrm{D}<0)$ may turn out to be a sustainable activity based on $\left(\frac{\Delta H}{\Delta D}\right) \leq\left(\frac{1-H}{1-D}\right)$.

These conditions compare percentage gap closure of $\mathrm{H}$ (benefits) and percentage damage of the existing quality of the NSE (costs). Meeting the above condition (for $\Delta \mathrm{D}>0$ ) can safeguard against a 'ruinous catastrophe.' As there is no unique sustainable human development path, by using policy parameters and choice variables, both conditions (for $\Delta \mathrm{D}>0$ or $\Delta \mathrm{D}<0$ ) can be customized to meet the needs of a nation or a community at a particular time. Once the sustainability condition is met, the goal should be to minimize the deadweight loss. Below we present the primary sustainability condition under two different scenarios:

Scenario I: Improvement in human development at the cost of the NSE

If the NSE deteriorates due to developmental activities the resulting increase in human development has to be such that the ratio of $\Delta \mathrm{H}$ to $\Delta \mathrm{D}$ is greater than or at least equal to a minimum threshold value, which will rule out the possibility of the natural and social environments, or natural and social capital, to ever fall below their critical levels until targeted $\mathrm{H}$ is reached. The targeted $\mathrm{H}$ can continuously be revised upward, as the UNDP does, to guarantee a livable environment forever. One of the advantages of this methodology is that it doesn't require macro planning over an infinite time horizon. (Note 8) As more data and information become available, they can 
be used to revise the parameter values in the sustainability condition to evaluate incremental human development.

Perceived risk parameter and discount factor can be added to the above condition to allow flexibility as may be needed in development planning depending on current states of $\mathrm{H}$ and D. Hence, the basic sustainability condition (SC) is

$$
\left(\frac{\Delta H}{\Delta D}\right) \geq \frac{1}{1+\delta}\left(\frac{1-H}{1-D}\right)^{\frac{\gamma}{1-\gamma}}
$$

where $\quad \mathrm{H}=$ the Human Development Index,

$\mathrm{D}=$ the damage index of the NSE,

$\Delta=$ positive or negative change,

$\delta=$ the discount factor. (Note 9) and

$\gamma=$ the risk-aversion parameter. (Note 10)

$\mathrm{H}, \delta$ and $\gamma$ are in $[0,1]$ and $\mathrm{D}$ is in $[0,1)$.

Re-arranging the terms, the sustainability condition can be written as

$$
\begin{aligned}
& (1+\delta) \frac{\frac{\Delta H}{(1-H)^{\frac{\gamma}{1-\gamma}}}}{\Delta D} \geq 1 \\
& (1-D)^{\frac{\gamma}{1-\gamma}} \\
& \text { or }(1+\delta)\left(\frac{\Delta H}{\Delta D}\right)\left(\frac{1-D}{1-H}\right)^{\frac{\gamma}{1-\gamma}} \geq 1
\end{aligned}
$$

The main distinction between the sustainability condition (SC) and the feasibility condition (FC) of CBA is that the SC does not require monetary valuation of all impacts. The numerical value of the left-hand side of the expression (2) or (3) can be called the Sustainable Human Development Index (SHDI henceforth), which can be used to assess and compare country performance or the performance of alternative projects in terms of SHD. To learn about the actual magnitude of change in human development (benefits) and damages to the NSE (costs), we must look at the values of the numerator and the denominator respectively in the left hand side of expression (1). (Note 11)

Scenario II: Environmental cleanup or any improvement in the NSE

Assume that $\Delta \mathrm{D}<0$, which implies an improvement in the quality of the NSE. Since an improvement in the NSE is expected to increase present and future well-being, any activity that improves the NSE at some loss in human development can still be considered a sustainable activity. Therefore, the basic sustainability condition is defined as

$$
\left(\frac{\Delta H}{\Delta D}\right) \leq \frac{1}{1+\delta}\left(\frac{1-H}{1-D}\right)^{\frac{\gamma}{1-\gamma}}
$$

Re-arranging the terms, the sustainability condition can be written as

$$
\begin{array}{r}
(1+\delta) \frac{\frac{\Delta H}{\frac{(1-H)^{\frac{\gamma}{1-\gamma}}}{\Delta D}}}{\frac{(1-D)^{\frac{\gamma}{1-\gamma}}}{\text { or }(1+\delta)\left(\frac{\Delta H}{\Delta D}\right)\left(\frac{1-D}{1-H}\right)^{\frac{\gamma}{1-\gamma}}} \leq 1} \leq 1
\end{array}
$$

In the sustainability index, the risk-perception parameter $\gamma$ is a policy instrument, which is partly determined by the current level of development and the quality of the NSE. A note of caution is that too high or too low $\gamma$ can cause a high level of inefficiency. 


\section{Results and Discussions}

This section compares the primary condition for a sustainable human development with the feasibility condition of cost-benefit analysis and computes the deadweight loss. It also presents a brief note on project evaluations with sustainability and feasibility conditions.

\subsection{The primary condition for SHD and the feasibility condition of CBA}

The primary condition for a sustainable human development (SHD) and the feasibility condition of cost-benefit analysis (CBA) may not be synonymous due to methodological differences. If the Kaldor-Hicks criterion, which is the basis of CBA, is extended to include the future generations' rights, Dewan's (2009) sustainability condition will meet the criterion. (Note 12) Besides separate environmental impact assessments (EIA), in practice, many cost-benefit analyses strive for incorporating monetary values of externalities. However, they fall short of ensuring 'sustainability' as envisioned by many outside the mainstream economics paradigm.

According to CBA, a project is viable if

Discounted flow of benefits $\geq$ Discounted flow of costs

$\Rightarrow \Delta \mathrm{Y}_{\mathrm{m}} \geq \Delta \mathrm{D}_{\mathrm{m}}$

$\Rightarrow \frac{\Delta Y_{m}}{\Delta D_{m}} \geq 1$, where $\Delta \mathrm{Y}_{\mathrm{m}}=$ the discounted flow of benefits or the present value (PV) of the income generated

from the project and $\Delta \mathrm{D}_{\mathrm{m}}=$ the discounted flow of costs or the present value (PV) of the monetary costs of the project.

On the other hand, the proposed condition for SHD is

$$
\frac{\Delta H}{\Delta D} \geq \frac{1}{1+\delta}\left(\frac{1-H}{1-D}\right)^{\frac{\gamma}{1-\gamma}} \text { or } S H D I \geq 1, \text { for any }
$$

positive damage to the NSE. One of the advantages of the sustainability condition (SC) or the sustainable human development index (SHDI) over CBA is that unlike CBA, SC or SHDI is not prone to valuation error. To compare CBA and SHDI (Note 13), we need to consider several cases:

$\underline{\text { Case I }}$

Assume that $\mathrm{H}=\mathrm{D}$ (Note 14$), \Delta \mathrm{D} \geq 0, \delta=0$ and $\gamma=0.5$, then

$$
\begin{aligned}
& \text { SHDI } \geq 1 \Rightarrow \frac{\Delta H}{\Delta D} \geq 1 \\
& \Rightarrow \frac{1}{3}\left(\frac{\Delta y^{i}+\Delta E_{d}+\Delta L}{\Delta D}\right) \geq 1,
\end{aligned}
$$

where $y^{\mathrm{i}}=$ adjusted per capita real income (PPP\$) index,

$\mathrm{E}_{\mathrm{d}}=$ educational attainment index, and

$\mathrm{L}=$ longevity index.

All variables are in $[0,1]$.

In general, the changes in $\mathrm{E}_{\mathrm{d}}$ and $\mathrm{L}$ are much slower than the change in $\mathrm{y}^{\mathrm{i}}$ (UNDP, 1991). Therefore, $\left(\Delta \mathrm{E}_{\mathrm{d}}+\Delta \mathrm{L}\right)$ $<2 \Delta y^{\mathrm{i}}$.

$$
\Rightarrow \frac{\Delta H}{\Delta D}<\frac{\Delta y^{i}}{\Delta D}
$$

According to Atkinson's formula for the utility of income, which the UNDP initially used to calculate adjusted real GDP for the Human Development Index, for a nation with per capita real income (PPP\$) less than the world average income, $\Delta y=\Delta y_{m}$ and for a nation with per capita real income (PPP\$) greater than the world average income, $\Delta \mathrm{y}<\Delta \mathrm{y}_{\mathrm{m}}$, where $\Delta \mathrm{y}$ and $\Delta \mathrm{y}_{\mathrm{m}}$ are changes in adjusted and actual per capita real income respectively. (Note 15) The UNDP's current methodology uses the log of per capita income to calculate the GDP index. (Note 16) Therefore, $\Delta \mathrm{y}<\Delta \mathrm{y}_{\mathrm{n}}$

The inequalities, (7) and (8), are significant for deriving relationships between the growth rates of human development $(\mathrm{H})$; adjusted per capita real income (PPP\$) index $\left(\mathrm{y}^{\mathrm{i}}\right)$; adjusted and actual per capita real income, y and $\mathrm{y}_{\mathrm{m}}$ respectively; and adjusted and actual real income, $\mathrm{Y}$ and $\mathrm{Y}_{\mathrm{m}}$ respectively. For any positive population growth rate (n), the growth rate of $y_{m}$ is smaller than the growth rate of $Y_{m}$. Therefore, $\% \Delta H<\% \Delta y^{i}<\% \Delta y$ 
$<\% \Delta \mathrm{y}_{\mathrm{m}}<\% \Delta \mathrm{Y}_{\mathrm{m}} \forall \mathrm{n}>0$ (9) Multiplying both sides of (8) by the population, we find that

$$
\begin{aligned}
& \Delta \mathrm{Y}<\Delta \mathrm{Y}_{\mathrm{m}} \\
& \Rightarrow \frac{\Delta Y}{\Delta D_{m}} \prec \frac{\Delta Y_{m}}{\Delta D_{m}} \quad \forall \mathrm{D}_{\mathrm{m}}>0 \\
& \Rightarrow S H D I \prec B C R\left(\frac{\Delta D_{m}}{\Delta Y}\right)\left(\frac{\Delta H}{\Delta D}\right)
\end{aligned}
$$

In equation (11), the numerical value of SHDI is smaller than the numerical value of the Benefit-Cost Ratio (BCR), if $\left(\frac{\Delta D_{m}}{\Delta Y}\right)\left(\frac{\Delta H}{\Delta D}\right) \leq 1$ or $S H D I \leq \frac{\Delta Y}{\Delta D_{m}}$

In other words, if the monetary cost of a project times SHDI is not greater than the log-adjusted income generated from the project, the sustainability condition is certainly more stringent than the feasibility condition of CBA in project-evaluation. Expression (12) can be re-arranged to find the condition:

$$
\Delta Y_{m} \geq e^{S H D I^{*} \Delta D_{m}}
$$

If this condition holds, a project may be feasible in terms of CBA, but the resulting human development may not be sustainable. As showed in (10), it is impossible for a change in income $\left(\Delta \mathrm{Y}_{\mathrm{m}}\right)$ to be smaller than or equal to a change in the log of income $(\Delta \mathrm{Y})$; therefore, the sustainability condition is always more conservative than the feasibility condition of CBA in this case.

From expression (9), we can derive another relationship between SHDI and BCR:

$$
\begin{aligned}
\% \Delta \mathrm{H}<\% \Delta \mathrm{Y}_{\mathrm{m}} \forall \mathrm{n}>0 \\
\Rightarrow \frac{\Delta H}{H} \prec \frac{\Delta Y_{m}}{Y_{m}} \\
\Rightarrow\left(\frac{\Delta H}{\Delta D}\right)\left(\frac{\Delta D}{H}\right) \prec\left(\frac{\Delta Y_{m}}{\Delta D_{m}}\right)\left(\frac{\Delta D_{m}}{Y_{m}}\right) \ldots \\
\Rightarrow S H D I \prec B C R\left(\frac{\Delta D_{m}}{\Delta D}\right)\left(\frac{H}{Y_{m}}\right) \ldots \ldots
\end{aligned}
$$

In equation (15), the numerical value of SHDI is smaller than the numerical value of BCR, if $\left(\frac{\Delta D_{m}}{\Delta D}\right)\left(\frac{H}{Y_{m}}\right)$

$$
\leq 1 \text { or } \Delta D_{m} \leq\left(\frac{Y_{m}}{H}\right)(\Delta D)
$$

That means if the monetary damage is not greater than $\frac{Y_{m}}{H}$ multiple of the physical damage index, the sustainability condition is more conservative than the feasibility condition of CBA. In other words, if the ratio of monetary to physical damage index is not greater than $\frac{Y_{m}}{H}$, the numerical value of SHDI is smaller than the numerical value of BCR. If the opposite is true, SHDI $B$ BCR.

Case II

Assume that $\mathrm{H}>\mathrm{D}$ (Note 17), $\Delta \mathrm{D} \geq 0, \delta=0$ and $\gamma=0.5$, then

$$
\begin{aligned}
\text { SHDI } & \geq 1 \Rightarrow \frac{\Delta H}{\Delta D} \geq\left(\frac{1-H}{1-D}\right) \\
\Rightarrow \frac{\Delta H}{\Delta D} & \geq 1-\mathrm{X}, \text { where } \mathrm{X}=\left(\frac{H-D}{1-D}\right)>0 .
\end{aligned}
$$


The sustainability condition in this case is more stringent than the feasibility condition of CBA, but it is not as stringent as the sustainability condition in Case I.

From inequality (14), we can find that

$$
\begin{aligned}
& \left(\frac{\Delta H}{\Delta D}\right)\left(\frac{\Delta D}{H}\right)\left(\frac{1-D}{1-H}\right) \prec\left(\frac{\Delta Y_{m}}{\Delta D_{m}}\right)\left(\frac{\Delta D_{m}}{Y_{m}}\right)\left(\frac{1-D}{1-H}\right) \\
& \Rightarrow S H D I \prec B C R\left(\frac{\Delta D_{m}}{\Delta D}\right)\left(\frac{H}{Y_{m}}\right)\left(\frac{1-D}{1-H}\right) \text {... }
\end{aligned}
$$

In (18), the numerical value of SHDI is smaller than the numerical value of BCR, if

$$
\begin{gathered}
\left(\frac{1-D}{1-H}\right) \leq 1 \\
\Rightarrow\left(\frac{\Delta D_{m}}{\Delta D}\right)\left(\frac{H}{Y_{m}}\right) \leq 1-\mathrm{X} \ldots
\end{gathered}
$$

Case III

Assume that $\mathrm{H}<\mathrm{D}$ (Note 18$), \Delta \mathrm{D} \geq 0, \delta=0$ and $\gamma=0.5$, then

$$
\begin{aligned}
& \text { SHDI } \geq 1 \Rightarrow \frac{\Delta H}{\Delta D} \geq\left(\frac{1-H}{1-D}\right) \\
& \Rightarrow \frac{\Delta H}{\Delta D} \geq 1+\mathrm{Z}, \text { where } \mathrm{Z}=\left(\frac{D-H}{1-D}\right)>0 \\
& \Rightarrow \frac{\Delta H}{\Delta D} \gg 1
\end{aligned}
$$$$
\left(\frac{\Delta D_{m}}{\Delta D}\right)\left(\frac{H}{Y_{m}}\right)
$$

The sustainability condition in this case is not only more stringent than the feasibility condition of CBA; it is also more stringent than the sustainability conditions in the other two cases. From expression (19), we can find that

$$
\left(\frac{\Delta D_{m}}{\Delta D}\right)\left(\frac{H}{Y_{m}}\right) \leq 1+\mathrm{Z}
$$

If condition (20) holds, the numerical value of SHDI is smaller than the numerical value of BCR.

The above conditions lead to the following propositions:

Proposition I: If $S H D I \leq \frac{\Delta Y}{\Delta D_{m}}$ or $\Delta Y_{m} \geq e^{S H D I^{*} \Delta D_{m}}$, the sustainability condition is more conservative than the feasibility condition of CBA.

Proposition II: Unlike the feasibility condition of CBA, the sustainability condition is different in different sustainable development regions. The sustainability condition is the most stringent in the unsustainable development region and the least stringent in the sustainable development region.

Proposition III: The sustainability condition is more conservative than the feasibility condition of CBA, if $\left(\frac{\Delta D_{m}}{\Delta D}\right)\left(\frac{H}{Y_{m}}\right) \leq 1+\mathrm{K}$, where $\mathrm{K}=0,-\mathrm{X}$ or $\mathrm{Z}$ depending on whether the economy is on the critical path of sustainable development, in the sustainable development region or in the unsustainable development region respectively.

The reasons for the sustainability condition to be different from the feasibility condition is due to the fact that there may not be a one-to-one relationship between monetary and physical damage, and also changes to the human development index may not be proportional to the incomes generated from a project. To be more conservative or risk-averse, one may suggest that a project be undertaken if, and only if, it meets both the feasibility condition of CBA and the sustainability condition in local, national and also in global sense. If that means a sub-optimal choice based on CBA, the deadweight loss can be calculated, and that can be deemed as uncertainty or sustainability premium. (Note 19) 


\subsection{The deadweight loss}

Since the sustainability condition may require more restrictive use of resources than what the feasibility condition of CBA would require, the sustainable level of human development is likely to be lower than the optimum level of human development. Hence, there is a potential for efficiency loss.(Note 20) In Figure 1, SEL amounts to the deadweight loss, when $\mathrm{H}=\mathrm{D}$ and marginal human development (MH) to marginal damage (MD) curve and marginal benefit (MB) to marginal cost (MC) curve are as shown. Since the ratio of marginal gains (MH or MB) to marginal losses (MD or MC) may not decline at the same rate for all developmental activities, the two curves may very well be non-linear.

\subsection{Project evaluations with sustainability and feasibility conditions}

CBA determines the feasibility of a project based on monetary estimates of the impact. The application of CBA diverges greatly from the textbook version of CBA, which can be seen in many case studies in Brouwer and Pearce (2005). When it comes to evaluate the effects of a project on sustainable human development, neither the monetary cost-benefit analysis (CBA) nor the environmental impact assessment (EIA) can be adequate. Presently, Canada, for example, uses 11 EIA techniques; (Note 21) the inclusion of sustainability condition as a project evaluation method would help measure additional dimensions of sustainability.

It is possible for a project to meet the basic sustainability condition from national perspective, but not from the local perspective. That's why sometimes the central government's plans are found to trigger unrest in the project area. To be conservative, a project should be carried on only if all necessary conditions for CBA and EIA along with local, regional, national and global sustainability conditions are met. These additional constraints will likely cause deadweight loss, but they will ensure a sustainable human development.

\section{Conclusions}

The feasibility condition of the cost-benefit analysis (CBA) uses monetary estimates of the impact for project or policy evaluations. It can be used to find an optimum level of economic activity, but it cannot guarantee the sustainability of the outcome of such activity. Therefore, the feasibility condition alone cannot be used to determine the sustainable level of human development. The primary condition for a sustainable human development, on the other hand, uses a composite index, called the Sustainable Human Development Index (SHDI), to determine the sustainability of a human development policy. The SHDI is an index based on the Human Development Index and a damage index. By including both monetary and non-monetary indicators, the computational methodology of SHDI combines both economic and scientific approaches to sustainability. Since the feasibility condition of CBA and the primary condition for a sustainable human development (SHD) are usually not synonymous, there will be a deadweight loss due to meeting the primary condition for SHD.

By re-defining SHDI and/or by using appropriate policy parameters, the primary condition for SHD can be customized for the needs of any nation or region. That is appropriate because the level of economic development, the nature of damage to the natural and social environments (NSE), social perceptions, etc. are not the same everywhere. Since the value of SHDI is a function of the level of human development and the level of damage to the NSE, equal changes in the Human Development Index and the NSE will yield different values for SHDI in different nations or regions. This is a significant difference between the static methodology of CBA and the more robust methodology of SHDI.

To sum up, the primary condition for a sustainable human development, in general, does not meet the feasibility condition of CBA, but it is a useful tool to determine the sustainable level of human development.

\section{Acknowledgements}

I am grateful to the anonymous referee for his/her very useful and constructive comments.

\section{References}

Alfsen, et al. (1987). Natural Resource Accounting and Analysis: The Norwegian experience 1978-1986. Social and economic studies, No. 65, Central Bureau of Statistics of Norway.

Arrow, K. and Fisher, A. (1974). Environmental preservation, uncertainty, and irreversibility. Quarterly Journal of Economics, Vol. 88.

Bartelmus, P. (2001). Accounting for sustainability: Greening the national accounts. In: M. K. Tolba (Eds.), Our Fragile World, Forerunner to the Encyclopaedia of Life Support System. Vol. 2, pp. 1721-1735.

Beckerman, W. (2007). The Chimera of 'Sustainable Development'. Electronic Journal of Sustainable Development. Vol. 1, Issue 1. 
Beckerman, W. and Hepburn, C. (2007). Ethics of the discount rate in the Stern Review on the Economics of Climate Change. World Economics, 8(1).

Boardman, et al. (2006). Cost-Benefit Analysis: Concepts and Practice, $3^{\text {rd }}$ edition. Prentice Hall, NJ.

Bojö, et al. (1990). Environment and Development: An Economic Approach, Kluwer Academic Publishers, Boston.

Brouwer, R. and Pearce, D. (Eds.) (2005). Cost-Benefit Analysis and Water Resources Management, Edward Elgar, UK.

Brundtland Commission. (1987). Our Common Future, Oxford University Press, Oxford.

Dewan, A. H. (1998). Measuring Sustainable Development: Problems and Prospects, Ph.D. dissertation, The University of Texas, Austin.

Dewan, H. (2009). Re-Defining Sustainable Human Development to Integrate Sustainability and Human Development Goals. The International Journal of Environmental, Cultural, Economic and Social Sustainability, Vol. 5, No. 4, pp. 147-162, Common Ground Publishing, Australia.

Dovers, et al. (1996). Uncertainty, sustainability, ecology and policy. Biodiversity and Conservation 5, 1143-1167.

Dubourg, R. and Pearce, D. (1996). Paradigms for environmental choice: Sustainability verses optimality. In: Faucheux, S., et al. (Eds.), Models of Sustainable Development.

Dupuit, J. (1844). On the measurement of the utility of public works. Translated in International Economic Papers, Vol. 2. Macmillan, London.

Ecological Economics (2007), Vol. 63, Issue 4, pp. 637-832.

Elkington, J. (1998). Cannibals with Forks: the Triple Bottom Line of 21 st Century Business.

Flyvbjerg, et al. (2002). Underestimating Costs in Public Works Projects: Error or Lie? Journal of the American Planning Association 68 (3), 279-295.

Flyvbjerg, et al. (2005). How (In)accurate Are Demand Forecasts in Public Works Projects? The Case of Transportation. Journal of the American Planning Association, 71 (2), 131-146.

Franklin. (1772). Letter to Joseph Priestley. In: Mott, F. and C. Jorgenson, B. Franklin (Eds.), Representative Selections with Introduction, Bibliography and Notes, American Book Company, NY.

Gowdy, J. (2007). Toward an experimental foundation for benefit-cost analysis. Ecological Economics 63, 649-655.

Gowdy, J. and Howarth, R. (2007). Sustainability and benefit-cost analysis: Theoretical assessments and policy options. Preface in Ecological Economics 63, 637-638.

Hall, J. (1993). Critical Load Maps: Europe and the UK. Paper presented to the conference: Acid Rain and Its Impacts: The Critical Loads Debate. University College London.

Harrington, et al. (2000). On the Accuracy of Regulatory Cost Estimates. Journal of Policy Analysis and Management 19 (2), 297-322.

Hartwick, J. M. (1978). Substitution among exhaustible resources and intergenerational equity. Review of Economic Studies 45.

Hasegawa, S. (2001). Development Cooperation. Presented in the UNU Global Seminar on Global Issues and the United Nations, Nov 20, 2001.

Hicks, J. R. (1940). The Valuation of the Social Income. Economica 7(26), pp. 105-124.

Howarth, R. (2007). Towards an operational sustainability criterion. Ecological Economics 63, 656-663.

Hueting, R. (1991). Correcting National Income for environmental losses: A practical solution for a theoretical dilemma. In: Costanza, R. (Ed.), Ecological Economics: The Science and Management of Sustainability, Columbia University Press, NY.

Hueting, R. (1992). In: UNEP, Summary Record: Workshop on Environmental and Natural Resource Accounting.

Iovanna, R. and Newbold, S. (2007). Ecological sustainability in policy assessments: A wide-angle view and a close watch. Ecological Economics 63, 639-648. 
Jolly, R. (1991). Statement to the Third Session of UNCED Preparatory Committee, 1991. Quoted in Taylor-Ide and Taylor (1995).

Kaldor, N. (1939). Welfare Propositions of Economics and Interpersonal Comparisons of Utility. Economic Journal 49 (195), pp. 549-552.

Knetsch, J. (2007). Biased valuations, damage assessments, and policy choices: The choice of measure matters. Ecological Economics 63, 684-689.

Laibson, D. (1997). Golden eggs and hyperbolic discounting. Quarterly Journal of Economics 112, 443-477.

Marshall, A. (1890). Principles of Economics: An Introductory Volume.

Nordhaus, W. (2007). A Review of the Stern Review of the Economics of Climate Change. Journal of Economic Literature. Vol. 45, Issue 3, pp. 686-702.

Norgaard, R. (1992). In: UNEP, Summary Record: Workshop on Environmental and Natural Resource Accounting.

Norton, B. (2005). Sustainability: A Philosophy of Adaptive Ecosystem Management, University of Chicago Press, Chicago.

Nussbaum, M. (2000). Women and Human Development, University of Chicago Press, Chicago.

Pinter, et al. (2005). Sustainable Development Indicators: Proposals for the Way Forward, Prepared for the UN Division for Sustainable Development. IISD, December, 2005.

Runnalls, D. (2008). Speech at the Globe 2008 Conference on Business and the Environment, March 12-14, Vancouver, BC.

Sagoff, M. (1998). Aggregation and deliberation in valuing environmental public goods: a look beyond contingent pricing. Ecological Economics 24 (2-3), 213-230.

Sen, A. K. (1999). Development as Freedom. Anchor Books. New York.

Solow, R. (1974). Intergenerational equity and exhaustible resources. Review of Economic Studies 41 (supplement).

Spangenberg, J. H. (2005). Economic sustainability of the economy: Concepts and indicators. International Journal of Sustainable Development.

Spash, C. (2007). Deliberative monetary valuation (DMV): Issues in combining economic and political processes to value environmental change. Ecological Economics 63, 690-699.

Speth. (1994). The Foreword to the 1994 Human Development Report, UNDP.

Stern, N. (2006). Stern Review on the Economics of Climate Change, UK Government Economic Service, London.

Swartzman, et al. (Eds.) (1982). Cost-benefit analysis and environmental regulations: Politics, ethics and methods, Washington, DC

Taylor-Ide and Taylor. (1995). Community Based Sustainable Human Development. Primary Environmental Care (PEC) Discussion Papers on Children, Environment and Sustainable Development, No. 1, Feb 1995.

Theys, J. (1989). Environmental Accounting in Development Policy: The French Experience. In: Ahmad, et al. (Eds.), Environmental Accounting for Sustainable Development, The World Bank, Washington, DC.

UN. (1993). Handbook of National Accounting: Integrated Environmental and Economic Accounting UNDP. Human Development Report, various issues.

UNEP. (1992). Summary Record: Workshop on Environmental and Natural Resource Accounting.

UNESCO. (2010). Sustainable Development. [Online] Available: http://portal.unesco.org/en/ev.php-URL_ID=4002\&URL_DO=DO_TOPIC\& URL_ SECTION $=201 . \mathrm{html}$ on $06 / 11 / 10$.

Weitzman, M. (2001). Gamma Discounting. The American Economic Review. Vol. 91, No. 1, pp. 260-271.

Weitzman, M. (2007). A Review of the Stern Review on the Economics of Climate Change. Journal of Economic Literature, Vol. 45, Issue 3, pp. 703-724.

Zerbe, R. and Dively, D. (1994). Benefit-Cost Analysis: In Theory and Practice, HarperCollins College Publishers, New York. 


\section{Notes}

Note 1. Some prefer the term Benefit-Cost Analysis (BCA) to Cost-Benefit Analysis (CBA), because historically, the term BCA was used when analyzing economic, ethical and philosophical issues, and CBA was used for evaluating more mechanical issues, e.g., by engineers and scientists (see Swartzman, et al., 1982; Zerbe and Dively, 1994). That distinction in a multi-disciplinary study like this is rather unnecessary.

Note 2. The NSE includes environment, natural resources, natural amenities, and socio-cultural, political and institutional conditions. Therefore, natural and social capital and what sociologists call cultural capital are part of the NSE. Some may argue that (environmental) sustainability issue is not about computing benefits and costs; it is about ensuring sustainable levels of ecological resources. Our argument is that in addition to ascertaining critical levels of the NSE, a benefit-cost comparison is important for minimizing the deadweight loss or the sustainability premium.

Note 3. The UNDP's Human Development Index is a measure of the level of human development. It is a composite index based upon equal weights on income, level of education, and longevity. In this paper, we use the Human Development Index to measure progress in human development. Therefore, an improvement in human development and an improvement in the Human Development Index are used indistinguishably throughout the paper.

Note 4. Critical levels for different environmental elements are defined in many scientific studies. For exhaustible natural resources, many countries' development plans consider certain quantity of reserve as critical. For social conditions index, ethnocentric values as well as globally accepted human rights along with other pertinent factors need to be weighed and compared against the 'baseline profiles.' Dewan (1998) also proposed some methodologies to define such critical levels.

Note 5. Jolly's statement to the Third Session of UNCED Preparatory Committee, 1991. Quoted in Taylor-Ide and Taylor (1995)

Note 6. The damage index is defined as: $\mathrm{D}=\operatorname{Max}\{\mathrm{ENV}, \mathrm{NAT}, \mathrm{AMN}, \mathrm{SOC}\}$, where ENV $=$ an index for environmental degradation, NAT $=$ an index for natural resource depletion, $\mathrm{AMN}=$ an index for the destruction of natural amenities, and $\mathrm{SOC}=$ an index for the change or degradation of socio-cultural-political and institutional conditions. All indices are in $[0,1]$. Since maximum damage to a sub-system of the NSE is used to calculate $\mathrm{D}$, the coefficient of variation $(\mathrm{V})$ of various damage indices also needs to be monitored. The computational details of the sub-indices are beyond the scope of this paper. The justification for using the worst condition of a subsystem of the NSE as the damage index is because each subsystem 'has to have the capability to maintain its capability to survive and evolve' (Spangenberg, 2005).

Note 7. Since the sustainability condition may cause an economy to deviate from the optimum level of economic activity, the resulting loss can be called the sustainability premium. Because of the non-availability of full information and the uncertainty about the future, over or under conservation due to meeting a sustainability condition is a very real possibility. By continuous correction of the indices based on available information, the errors in decision can be minimized. That will minimize the uncertainty or sustainability premium.

Note 8. Macro planning may be required for other purposes.

Note 9. An improvement in the present Human Development Index (H) may have some positive effect on the future H. Many economic development studies show that better opportunities exist for children from more educated and rich parents. This spill over benefit is captured by the non-negative fraction $\delta$.

Note 10 . The sustainability condition requires that the ratio of a change in $\mathrm{H}$ to a change in $\mathrm{D}$ be not less than $\frac{\gamma}{1-\gamma}$ order of the ratio of a difference between targeted and actual $H$ to the quality of the NSE. The value of $\gamma$ determines the "degree of bias" toward further human development or conservation of resources and environment. Bias toward conservation means taking less risk about the future. Therefore, $\gamma$ can be interpreted as the "risk-aversion" parameter. $\gamma=0.5$ implies risk-neutrality.

Note 11 . The human development indices of different nations of the world are published annually by the UNDP in its Human Development Report.

Note 12. Kaldor (1939) and Hicks (1940). Boardman, et al. (2006) states the criterion as follows: "A policy should be adopted if and only if those who gain could fully compensate those who will lose and still be better off." 
Note 13. It is evident that the feasibility condition of CBA uses the PV of aggregate benefits and aggregate costs of a project, whereas the sustainability condition or the SHDI uses per capita benefits as measured by the human development index. Therefore, the same amount of environmental damage if benefits a few people or a large number of people will have differential effects on the value of SHDI.

Note $14 . \mathrm{H}=\mathrm{D}$ (measured on a one-point scale) means that the nation is on the 'critical path of sustainable development' (Dewan, 1998). If the damage elasticity of $\mathrm{H}, \mathrm{E}_{\mathrm{dh}}=1$, a nation on the critical path will exhaust the quality of the NSE to reach $\mathrm{H}=1$.

Note 15. See UNDP (1997).

Note 16. See UNDP (2009).

Note $17 . \mathrm{H}>\mathrm{D}$ means that the nation is in the 'sustainable development region' (Dewan, 1998). A nation in the sustainable development region can always reach $\mathrm{H}=1$ without exhausting the quality of NSE, if the damage elasticity of $\mathrm{H}, \mathrm{E}_{\mathrm{dh}}=1$.

Note 18. $\mathrm{H}<\mathrm{D}$ means that the nation is in the 'unsustainable development region' (Dewan, 1998). If the damage elasticity of $\mathrm{H}, \mathrm{E}_{\mathrm{dh}}=1$, a nation in the unsustainable development region will never reach $\mathrm{H}=1$.

Note 19. "The expected value of benefits under uncertainty is less than the value of benefits under certainty... Therefore, we should err on the side of under investment, rather than over investment, since development is irreversible." (Arrow \& Fisher, 1974)

Note 20. In the Solow (1974) and Hartwick (1978) framework, sustainable growth path is different from the optimal growth path, which means that sustainability can be achieved at the cost of efficiency. Norgaard (1992) asserts that efficiency is not the objective in sustainable development.

Note 21. The IISD President, David Runnalls, stated it in his speech at the Globe 2008 Conference on Business and the Environment.

\section{Optimum \& Sustainable Levels of Development}

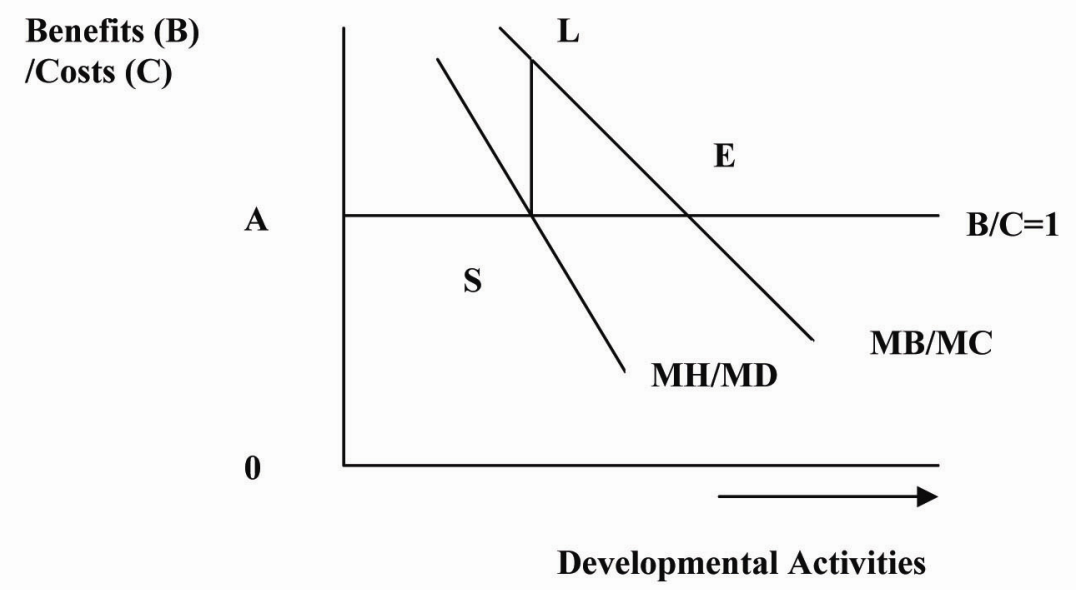

Figure 1. Optimum and sustainable levels of development 